\title{
Etanercept Clearance during an in vitro Model of Continuous Venovenous Hemofiltration
}

\author{
Geoffrey M. Fleming ${ }^{a}$ Noha N. Salamab, d Saada K. Eid ${ }^{c}$ Kenneth R. Cooke ${ }^{c}$ \\ Bruce A. Muellerb \\ a Department of Pediatrics, Division of Critical Care, Monroe Carell Jr. Children's Hospital at Vanderbilt, \\ Vanderbilt University, Nashville, Tenn., b University of Michigan College of Pharmacy, Ann Arbor, Mich., and \\ 'Department of Pediatrics, Division of Hematology Oncology, Rainbow Babies and Children's Hospital and \\ Case Western Reserve University School of Medicine, Cleveland, Ohio, USA; ${ }^{\mathrm{d}}$ Department of Pharmaceutics and \\ Industrial Pharmacy, Faculty of Pharmacy, Cairo University, Cairo, Egypt
}

\section{Key Words}

Etanercept · Continuous renal replacement therapy •

Hemofiltration

\begin{abstract}
Background/Aims: Etanercept is a tumor necrosis factor- $\alpha$ antagonist used in inflammation-mediated conditions. Continuous venovenous hemofiltration (CVVH) has also been used in patients with inflammatory conditions. This study evaluated etanercept clearance using an in vitro $\mathrm{CVVH}$ model. Methods: Etanercept clearance was assessed in vitro in bovine blood at 1-3 $\mathrm{mg} / \mathrm{l}$ final serum concentration, and urea control at $750 \mathrm{mg} / \mathrm{l}$. CVVH was performed using polyacrylonitrile, polysulfone, and polymethylmethacrylate filters at $3 \mathrm{I} / \mathrm{h}$ ultrafiltrate and $200 \mathrm{ml} / \mathrm{min}$ blood flow rates. Transmembrane clearance was estimated using sieving coefficient calculations, and adsorptive removal rate was approximated using a mass balance calculation. Results: Urea sieving coefficient remained constant $(1.04 \pm 0.01)$. Ultrafiltrate etanercept concentrations were undetectable (sieving coefficient $<0.02$ ) and transmembrane and adsorptive clearances were negligible. Conclusion: Etanercept is not cleared
\end{abstract}

appreciably by transmembrane or adsorptive mechanisms in CVVH using polyacrylonitrile, polysulfone, or polymethylmethacrylate hemofilters.

Copyright $\odot 2009$ S. Karger AG, Basel

\section{Introduction}

Therapeutic agents have evolved in recent decades and newer 'designer' chimeric immunomodulators are available for an expanding list of disease processes. Etanercept (Enbrel ${ }^{\circledR}$, Amgen Inc., Thousand Oaks, Calif., USA) is a soluble dimeric tumor necrosis factor- $\alpha$ (TNF- $\alpha$ ) binding protein that is used in many clinical situations involving inflammation. Approved indications for use in adults have expanded to include rheumatoid arthritis, ankylosing spondylitis, and psoriasis [1]. In the pediatric population, ongoing trials and off-label uses include inflammatory bowel disease, juvenile rheumatoid arthritis, uveitis, and idiopathic pneumonia syndrome related to stem cell transplantation [1-6]. Other therapeutic modalities, such as continuous venovenous hemofiltration $(\mathrm{CVVH})$, have been employed with success in some of the same disease

\section{KARGER}

Fax +41613061234 E-Mail karger@karger.ch www.karger.com
(C) 2009 S. Karger AG, Basel

$0253-5068 / 09 / 0284-0348 \$ 26.00 / 0$

Accessible online at:

www.karger.com/bpu
Geoffrey M. Fleming

Vanderbilt University, Department of Pediatrics

Division of Critical Care, Monroe Carell Jr. Children's Hospital at Vanderbilt

5121 DOT, 2200 Children's Way, Nashville, TN 37232-3467 (USA)

Tel. +1 615936 3968, Fax +1 615936 3467, E-Mail geoffrey.fleming@vanderbilt.edu 
processes where etanercept is used [7]. Although population pharmacokinetic studies of subcutaneously administered etanercept exist for both healthy volunteers and adult patients with rheumatoid arthritis, there are no published data regarding clearance of etanercept during $\mathrm{CVVH}$, although this modality has been documented to remove many other drugs [8-10]. Hence, literature supporting the use of etanercept and CVVH for disease processes such as idiopathic pneumonia syndrome requires an understanding of the interaction of these therapies when used concomitantly.

Etanercept is a large multimeric protein fabricated from 2 identical polypeptides consisting of the extracellular region of human TNF receptor p75 fused to the Fc portion of a human Ig, with a total molecular weight of $150 \mathrm{kDa}$. As such, this molecule is unlikely to undergo transmembrane clearance in commercially available hemofilters with molecular cut-offs of 25-30 kDa. Yet, due to larger pore size (at $100 \AA$ ), etanercept may cross into the ultrafiltrate (UF) during hemofiltration using polymethylmethacrylate (PMMA) hemofilters. In a study of chronic hemodialysis patients, PMMA filters (BK1, 6F Filtryzer $^{\circledR}$; Toray Industries, Tokyo, Japan) produced UF containing protein concentrations up to $1 \mathrm{~g} / \mathrm{l}$, including IgG at $180 \mathrm{kDa}$ in size [11].

Etanercept clearance through protein adsorption to the hemofilter membrane may also be an important clearance mechanism with polyacrylonitrile (AN69) and polysulfone (PS) membranes [12]. Deposition of protein is affected by properties of the membrane, but ranges from 15-75 $\mu \mathrm{g}$ of protein per $\mathrm{cm}^{2}$ for the most commonly used hemofilters worldwide $[12,13]$. Protein adsorption to all types of artificial membranes is well described, occurring in the first $20 \mathrm{~min}$ of blood-membrane interface [14-16]. This mode of clearance has previously been documented for other proteins, such as cytokines, in both laboratory and human studies of CVVH in sepsis [17-21]. Although protein adsorption occurs with AN69 and PS membranes, PMMA membranes were designed specifically for protein adsorption to limit $\beta_{2}$-microglobulin accumulation and to prevent dialysis-related amyloidosis [22]. Hence, these PMMA membranes may confer additional adsorptive clearance properties as compared to AN69 and PS membranes with regards to clinically relevant proteins.

The objective of this study was to evaluate the clearance of etanercept during $\mathrm{CVVH}$, as well as to evaluate the effects of time and filter type on this clearance. Two extracorporeal clearance mechanisms were evaluated for each filter type: transmembrane clearance and removal from the system by protein adsorption to the filter.

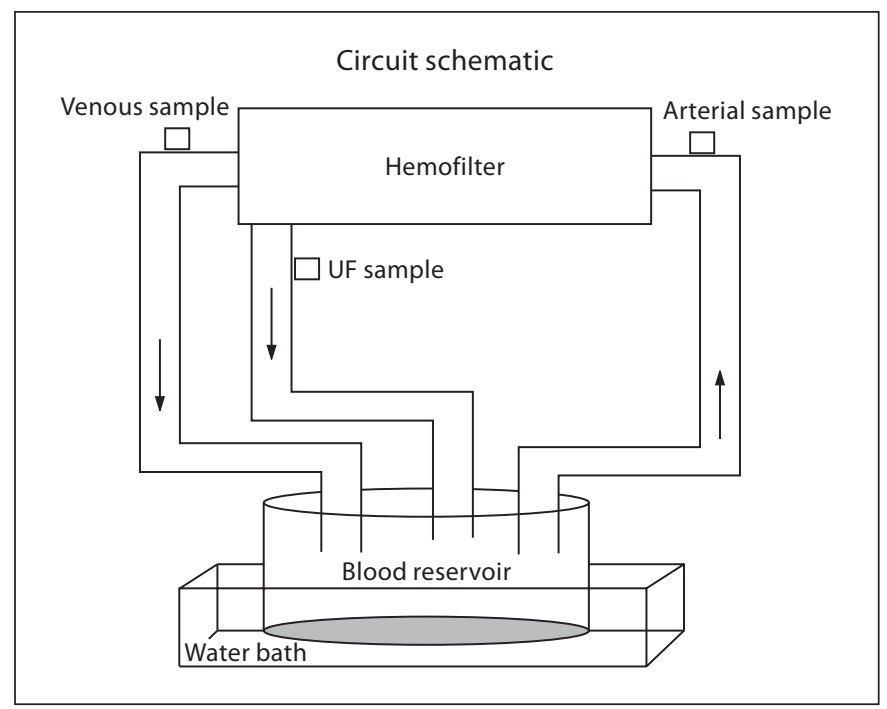

Fig. 1. In vitro CVVH model schematic. Blood is continuously circulated in the blood reservoir warmed in a water bath at $37^{\circ} \mathrm{C}$. UF is returned to the blood reservoir and sampling ports are available immediately before and after the hemofilters as indicated.

\section{Methods}

An in vitro model (fig. 1) of CVVH was previously developed and validated in our laboratory and has been used to generate clearance data for trace minerals and antimicrobials that has been validated in patients $[10,23,24]$. This model utilizes 1 liter of $\mathrm{pH}-$ regulated bovine whole blood (Animal Technologies, Tyler, Tex., USA), anticoagulated with $3.8 \%$ sodium citrate, placed in an Erlenmeyer flask submerged in a $37^{\circ} \mathrm{C}$ water bath as the venous blood reservoir.

\section{Blood Reservoir and Drug Preparation}

The blood reservoir was prepared by the addition of 5,000 IU heparin and $2 \mathrm{~g}$ of dextrose during continuous stirring. Urea was added to the blood reservoir to achieve an approximate blood urea nitrogen concentration of $75 \mathrm{mg} / \mathrm{dl}$. Following blood preparation, whole blood was drawn from the reservoir into 2 capillary tubes (SafeTec Clinical Products Inc., Ivylant, Pa., USA), which were then placed into a HemataStat II (Separation Technologies Inc., Valparaiso, Ind., USA) machine for hematocrit measurement. The 2 hematocrit values were averaged for the calculation of plasma volume prior to the addition of the study drug.

Etanercept was reconstituted as recommended by the manufacturer using sterile water to a final concentration of $25 \mathrm{mg} / \mathrm{ml}$. Etanercept was added to the venous reservoir to achieve a plasma concentration of $1-3 \mathrm{mg} / \mathrm{l}$ based on a calculated serum volume [blood volume $\times(1-$ hematocrit $)]$. The reservoir was stirred for 5 min prior to beginning hemofiltration.

\section{CVVH Technique}

We studied 3 filter types: AN69, (Multiflow $100^{\circledR}$; Gambro, Lakewood, Colo., USA), PS (Optiflux 160 ${ }^{\circledR}$; Fresenius Medical Care, Homburg, Germany), and PMMA (BK-2.1F Filtryzer ${ }^{\circledR}$; 
Toray Industries, Tokyo, Japan). CVVH was performed using the Braun-Diapact ${ }^{\circledR}$ system, including standard tubing packs (Diapact ${ }^{\circledR}$ CRRT Kit; B. Braun Medical Inc., Bethlehem, Pa., USA) used in clinical practice, with a new filter and tubing for each experiment. The circuit was initially prepared by normal saline priming following the manufacturer's instructions for each of the 3 types of hemofilters under study. UF was returned to the venous line by connecting the filter replacement fluid inlet line to the outlet of the UF collection bag, thus making a closed circuit. After 5 min of continuous stirring of the blood reservoir, the system was connected to the reservoir and allowed to circulate in $\mathrm{CVVH}$ mode for $240 \mathrm{~min}$. During CVVH, transmembrane pressure was recorded from the Diapact in serial fashion. Hemofiltration was performed with a blood flow rate of $200 \mathrm{ml} / \mathrm{min}$ with an ultrafiltration rate of $3,000 \mathrm{ml} / \mathrm{h}$.

\section{Data Collection}

All samples were obtained from the sampling ports in the circuit, including arterial, venous, and UF. Etanercept samples were obtained using 1-ml sterile syringes at 0 (baseline), 5, 10, 15, 20, $30,60,90,120,180$, and $240 \mathrm{~min}$. Samples were immediately placed into $5-\mathrm{ml}$ polystyrene tubes and centrifuged at 3,000 rpm for $10 \mathrm{~min}$. The supernatants were stored in cryovials at $-80^{\circ} \mathrm{C}$ until sample analysis. Identical sampling and sample processing techniques were used for blood urea nitrogen samples at 0 (background), 5, 60, 120, 180, and $240 \mathrm{~min}$.

\section{Data Analysis}

Urea concentrations from each sample were analyzed by a kinetic test with the absorbance measured at $\lambda=340 \mathrm{~nm}$ with a COBAS Integra ${ }^{\circledR} 400$ Plus (Roche Diagnostics, Indianapolis, Ind., USA). The coefficient of variation of the assay was $<10 \%$ and the blood urea nitrogen lower limit of detection was $1.8 \mathrm{mg} / \mathrm{dl}$. Etanercept concentrations were measured using cytokine enzymelinked immunosorbent assay (ELISA) according to the manufacturer's protocol (R\&D Systems, Minneapolis, Minn., USA). Briefly, human sTNF RII was captured by specific primary antibody and detected by horseradish peroxidase detection antibody (DuoSet reagents; R\&D Systems). The assay was then developed using $3,3^{\prime}, 5,5^{\prime}$-tetramethylbenzidine substrate (BD Biosciences, San Jose, Calif., USA). The absorbance was measured at $\lambda=450 \mathrm{~nm}$ using a microplate reader (ELx800; BioTek, Winooski, Vt., USA). Recombinant human sTNF RII was used for the preparation of standards (DuoSet Reagents; R\&D Systems). Samples and standards were run in duplicates. The coefficient of variation was estimated at $<11 \%$ with a detection range of $78-2,500 \mathrm{pg} / \mathrm{ml}$.

Extracorporeal clearance was calculated for urea and etanercept using the following equations:

blood sieving coefficient $=\left(\mathrm{C}_{\mathrm{UF}}\right) /\left(\mathrm{C}_{\mathrm{A}}\right)$

where $\mathrm{C}_{\mathrm{UF}}=$ concentration of solute in ultra filtrate and $\mathrm{C}_{\mathrm{A}}=\mathrm{con}$ centration of solute obtained from blood from arterial port;

transmembrane clearance $=(\mathrm{SC}) \times(\mathrm{Quf})$

where SC = blood sieving coefficient and (Quf) = ultrafiltration rate.

The prefilter (arterial) and postfilter (venous) etanercept concentrations were normalized to the prefilter blood flow rate $(\mathrm{Qb})$ $(200 \mathrm{ml} / \mathrm{min})$ and the postfilter flow rate $(\mathrm{Qb}-\mathrm{Quf}=150 \mathrm{ml} /$ min), to determine the amount of drug entering or exiting the filter per unit time (etanercept transfer rate), respectively. Adsorptive clearance was estimated by mass balance equation as follows: etanercept adsorptive clearance $=$ prefilter transfer rate (UF transfer rate + postfilter transfer rate).

\section{Statistical Analysis}

Power analysis was performed using a 1-tailed t test to detect a $20 \%$ change in drug concentration over $4 \mathrm{~h}$ of CVVH. Using $\alpha=0.05, \beta=0.15$, and assuming a standard deviation for drug measurement of $10 \%, 5$ filters were required in each group. SPSS statistical software version 14.0 was used to analyze the data. A linear mixed model was used to compare etanercept transfer rates, adsorptive clearance, and sieving coefficients across time using Bonferroni for post hoc analysis. G-criterion was used for testing outlier extreme values [25]. Statistical significance was set at $<0.05$.

\section{Results}

A total of 16 filters were studied, 5 each in the PS and AN69 arms of the study, and 6 in the PMMA group. The mean sieving coefficient for urea was $1.03 \pm 0.01,1.04 \pm$ 0.01 , and $1.05 \pm 0.06$ for the PS, AN69, and PMMA hemofilters, respectively, with no statistically significant difference for between and within group analysis $(\mathrm{p}>$ 0.05). Transmembrane pressure remained less than 300 $\mathrm{mm} \mathrm{Hg}$ for 14 of 15 filters at all time points. The urea and transmembrane pressure data suggest the filters performed as expected during the course of the experiment. Problems were encountered at 180-240 min in maintaining UF volumes at 3,000 $\mathrm{ml} / \mathrm{h}$ in the PMMA hemofilters. In these instances, the UF rate was reduced to maintain circuit patency, and ranged from 1,500 to $2,500 \mathrm{ml} / \mathrm{h}$.

The target initial etanercept plasma concentrations set in this study were $1-3 \mathrm{mg} / \mathrm{l}$. The initial mean etanercept concentrations were $1.15 \pm 0.44 \mathrm{mg} / \mathrm{l}, 1.24 \pm 0.47 \mathrm{mg} / \mathrm{l}$, and $1.4 \pm 0.6 \mathrm{mg} / \mathrm{l}$ for the PS, AN69, and PMMA hemofilters, respectively. Mean etanercept blood sieving coefficients were $0.001 \pm 0.002$ for both the PS and AN69 groups, respectively, and $0.002 \pm 0.003$ for the PMMA group. These data suggest negligible transmembrane clearance for etanercept by the filters under study.

Adsorptive clearance of etanercept was approximated with a mass balance equation. Since the UF content of etanercept was near zero, the arteriovenous difference becomes the approximation of protein adsorption. For the AN69 filter group, the arterial sample concentration measured at 90 min was censored because it was 2 - to 3fold higher compared to the remaining 10 sampling time points (G-criterion outlier testing), and the subsequent 


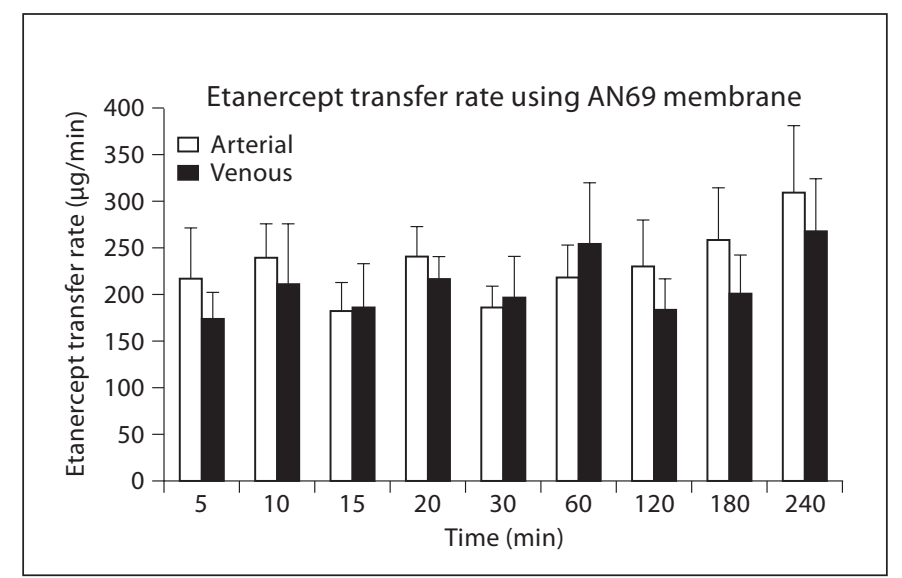

Fig. 2. Effect of time on the etanercept transfer rate $(\mu \mathrm{g} / \mathrm{min})$ for the AN69 filter group $(n=5)$.

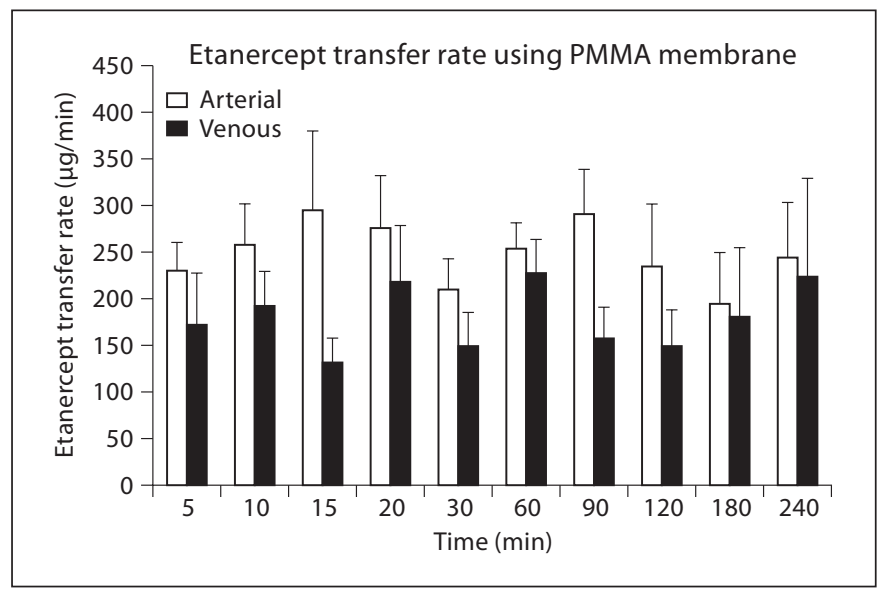

Fig. 4. Effect of time on the etanercept transfer rate $(\mu \mathrm{g} / \mathrm{min})$ for the PMMA filter group $(n=6)$.

analysis reflects exclusion of this time point. For the AN69 membrane, there were no significant differences in etanercept concentrations between the arterial samples as a function of time, nor was there any significant difference between arterial and venous etanercept sample concentrations at each time point. These findings collectively suggest the absence of demonstrable adsorptive clearance for etanercept by AN69 filters (fig. 2).

We detected similar findings with the PS hemofilters, with the exception of the sample at $240 \mathrm{~min}$ where there was a significant arteriovenous difference, as well as a significantly higher arterial etanercept concentration at

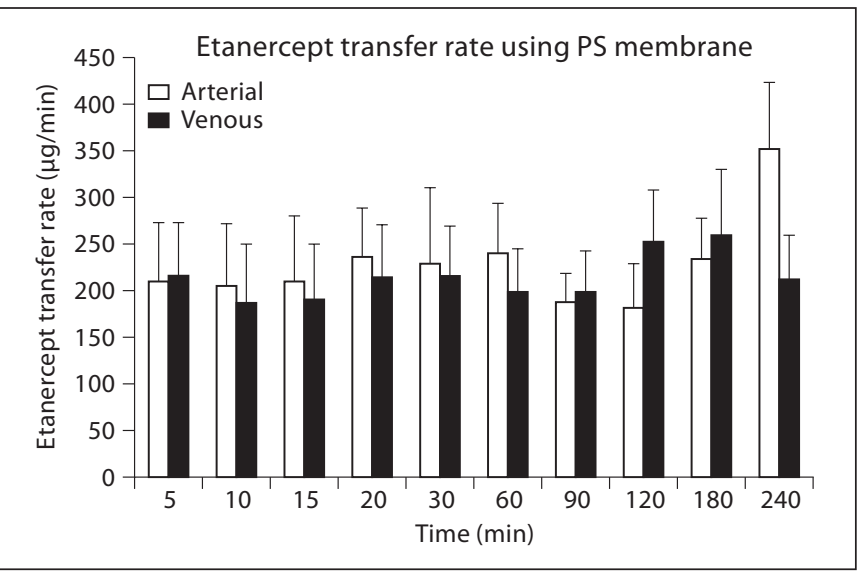

Fig. 3. Effect of time on the etanercept transfer rate $(\mu \mathrm{g} / \mathrm{min})$ for the PS filter group $(n=5)$.

240 min (considered an outlier based on G-criterion outlier testing), compared to all arterial concentrations up to $180 \mathrm{~min}$ ( $\mathrm{p}=0.001$; fig. 3 ). Data for the PMMA hemofilter group showed significant etanercept concentration differences between the arterial samples as well as arteriovenous differences at various time points (fig. 4). However, despite these findings, the mean arterial concentration at 240 min was not significantly different from the baseline concentration, suggesting no substantial drug was adsorbed to the PMMA membrane during the study.

\section{Discussion}

In this study, we did not find substantial CVVH clearance of etanercept by either extracorporeal clearance mechanism studied. Transmembrane clearances were exceedingly small by virtue of a SC of approximately 0.001 for AN69 and PS, suggesting that hemofiltration is not a meaningful form of etanercept elimination. PMMA filters were developed for the removal of $\beta_{2}$-microglobulin $(11 \mathrm{kDa})$ during chronic hemodialysis, and previous work with PMMA filters suggested molecules as large as $180 \mathrm{kDa}$ would pass through the membrane [11]; however, etanercept (molecular weight $150 \mathrm{kDa}$ ) also had a very small SC (0.002) in our study. In studies of cytokine clearance in sepsis with AN69 membranes, adsorption provided significant clearance for these proteins [26], yet adsorption of etanercept was below the level of detection for all hemofilters in our study. 
Limitations of this study include our use of a bovine blood model instead of a human blood model. Theoretically, etanercept binding could be different in bovine blood versus human blood. However, the rate-limiting step to etanercept crossing the hemofilter membrane is likely its large molecular weight $(150 \mathrm{kDa})$ rather than its protein binding. Also, we modeled the CVVH clearance when the plasma concentration was approximately $1-3$ $\mathrm{mg} / \mathrm{l}$. Obviously, a patient's plasma concentration will decline with time; however, the SC typically remains constant in $\mathrm{CVVH}$, regardless of drug plasma concentrations [10]. Additionally, the approximation of etanercept clearance via protein adsorption using mass balance is less precise than direct measurement of etanercept on used membranes. However, these limitations do not affect the primary goal of this study, which was to determine if a significant amount (20\%) of etanercept is removed from the system during $\mathrm{CVVH}$.

Indications for, and use of, both CVVH and etanercept are expanding, and knowledge of the interface of these 2 therapies is important. In pediatric patients with idiopathic pneumonia syndrome after stem cell transplantation, the addition of etanercept to the regimen has reduced mortality from nearly 70 to $21 \%[2,5]$. In this same group, CVVH has also reduced mortality [7] as well as multiorgan failure in other pediatric patients $[7,27]$. Although we report absence of substantial etanercept clearance by each of the 3 studied filter types, we feel these results are important to report. Our findings suggest that the investigated modalities (etanercept and $\mathrm{CVVH}$ ) exert their influence independently on outcomes as we found no evidence of changes in etanercept plasma concentration during CVVH in an in vitro model. These data do not suggest that there is a need for dosage alterations with etanercept during CVVH due to extracorporeal clearance.

\section{Acknowledgments}

Etanercept was provided by Amgen Inc. and PMMA filters were provided by Toray Industries for the purposes of this study. This work was supported in part by the Burroughs Wellcome Fund, Clinical Scientist Award in Translational Research (K. R.C.). Dr. Noha N. Salama was supported by Grant\#UL1RR024986 from the National Center for Research Resources (NCRR). The content is solely the responsibility of the authors and does not necessarily represent the official views of NCRR or the National Institutes of Health.

\section{References}

1 Weinberg JM, Bottino CJ, Lindholm J, Buchholz R: Biologic therapy for psoriasis: an update on the tumor necrosis factor inhibitors infliximab, etanercept, and adalimumab, and the T-cell targeted therapies efalizumab and alefacept. J Drugs Dermatol 2005;4:544555 .

2 Yanik GA, Uberti JP, Ferrara JLM, et al: Soluble tumor necrosis factor receptor: enbrel $\left(\right.$ Enbrel $\left.^{\circledR}\right)$ for the treatment of idiopathic pneumonia syndrome following allogeneic stem cell transplantation. Biol Blood Marrow Transplant 2004;10:89.

-3 Cooke KR, Hill GR, Gerbitz A, et al: Tumor necrosis factor-alpha neutralization reduces lung injury after experimental allogeneic bone marrow transplantation. Transplantation 2000;70:272-279.

4 Cooke KR, Gerbitz A, Crawford JM, et al: LPS antagonism reduces graft-versus-host disease and preserves graft-versus-leukemia activity after experimental bone marrow transplantation. JClin Invest 2001;107:15811589.

5 Yanik G, Hellerstedt B, Custer J, et al: Etanercept (Enbrel) administration for idiopathic pneumonia syndrome after allogeneic hematopoietic stem cell transplantation. Biol Blood Marrow Transplant 2002;8:395-400.
6 Sandborn WJ: New concepts in anti-tumor necrosis factor therapy for inflammatory bowel disease. Rev Gastroenterol Disord 2005;5:10-18.

7 DiCarlo JV, Alexander SR, Agarwal R, Schiffman JD: Continuous veno-venous hemofiltration may improve survival from acute respiratory distress syndrome after bone marrow transplantation or chemotherapy. J Pediatr Hematol Oncol 2003;25:801805.

8 Kuang D, Verbine A, Ronco C: Pharmacokinetics and antimicrobial dosing adjustment in critically ill patients during continuous renal replacement therapy. Clin Nephrol 2007;65:267-284.

-9 Böhler J, Donauer J, Keller F: Pharmacokinetic principles during continuous renal replacement therapy: drugs and dosage. Kidney Int Suppl 1999;72:S24-S28.

10 Churchwell MD, Pasko DA, Mueller BA: Daptomycin clearance during modeled continuous renal replacement therapy. Blood Purif 2006;24:548-554

-11 Mann H, Melzer H, Al-Bashir A, Xu XQ, Stiller S: Testing protein permeability of dialysis membranes using SDS-PAGE. Int J Artif Organs 2002;25:441-446.
12 Langsdorf LJ, Zydney AL: Effect of blood contact on the two transport properties of hemodialysis membranes: a two-layer membrane model. Blood Purif 1994;12:292-307.

13 Moachon N, Boullanger C, Fraud S, Vial E, Thomas M, Quash G: Influence of the charge of low molecular weight proteins on their efficacy of filtration and/or adsorption on dialysis membranes with different intrinsic properties. Biomaterials 2002;23:651-658.

14 Röckel A, Hertel J, Fiegel P, Abdelhamid S, Danitz N, Walb D: Permeability and second membrane formation of a high flux polysulfone hemofilter. Kidney Int 1986;30:429432.

15 Clark WR, Macias WL, Molitoris BA, Wang $\mathrm{NH}$ : Membrane adsorption of $\beta$ 2-microglobulin: equilibrium and kinetic characterization. Kidney Int 1994;46:1140-1146.

16 Clark WR, Macias WL, Molitoris BA, Wang $\mathrm{NH}$ : Plasma protein adsorption to highly permeable hemodialysis membranes. Kidney Int 1995;48:481-488

17 Yekebas EF, Eisenberger CF, Ohnesorge $\mathrm{H}$, et al: Attenuation of sepsis-related immunoparalysis by continuous veno-venous hemofiltration in experimental porcine pancreatitis. Crit Care Med 2001;29:1423-1430. 
18 Cole L, Bellomo R, Davenport P, Tipping P, Ronco C: Cytokine removal during continuous renal replacement therapy: an ex vivo comparison of convection and diffusion. Int J Artif Organs 2004;27:388-397.

19 Kellum JA, Dishart MK: Effect of hemofiltration filter adsorption on circulating IL-6 levels in septic rats. Crit Care 2002;6:429 433.

20 Ronco C, Ricci Z, Bellomo R: Importance of increased ultrafiltration volume and impact on mortality: sepsis and cytokine story and the role of continuous veno-venous haemofiltration. Curr Opin Nephrol Hypertens 2001;10:755-761.
21 Ronco C, Inguaggiato P, D'Intini V, et al: The role of extracorporeal therapies in sepsis. J Nephrol 2003;16:S34-S41.

22 Bonomini M, Fiederling B, Bucciarelli T, Manfrini V, Di Ilio C, Alvertazzi A: A new polymethylmethacrylate membrane for hemodialysis. Int J Artif Org 1996;19:232-239.

-23 Nakamura AT, Btaiche IF, Pasko DA, Jain JC, Mueller BA: In vitro clearance of trace elements via continuous renal replacement therapy. J Ren Nutr 2004;14:214-219.

24 Churchwell MD, Pasko DA, Btaiche IF, Jain JC, Mueller BA: Trace element removal during in vitro and in vivo continuous hemodialysis. Nephrol Dial Transplant 2007;22: 2970-2977.
25 Bolton S: Statistics; in Gennaro AR (ed): Remington's Pharmaceutical Sciences. 18th edition. Easton, Mack Publishing, 1990, pp 104-137.

26 De Vriese AS, Colardyn FA, Philippé JJ, Vanholder RC, De Sutter JH, Lameire NH: Cytokine removal during continuous hemofiltration in septic patients. J Am Soc Nephrol 1999; 10:846-853.

27 Goldstein SL, Somers MJ, Baum MA, et al: Pediatric patients with multi-organ dysfunction syndrome receiving continuous renal replacement therapy. Kidney Int 2005;67: 653-658. 